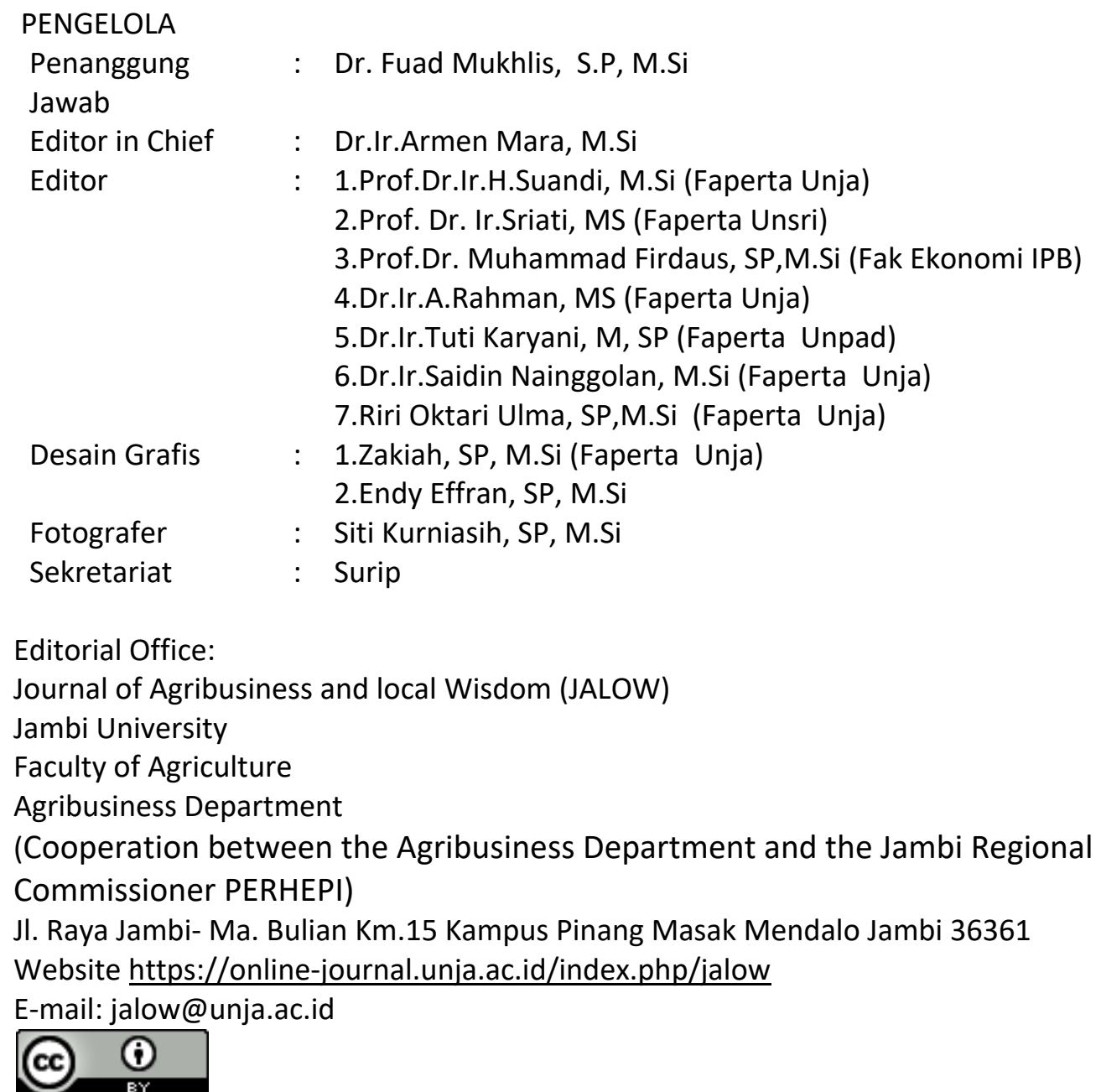

This work is licensed under a Creative Commons Attribution 4.0 International License. 


\section{Assalamualaikum wbwb}

\section{PENGANTAR}

Kondisi agribisnis tahun 2020 ini agak berbeda dengan tahun sebelumnya. Kebijakan penanggulangan Covid19 seperti "dirumah Aja, lockdown lokasi, Isolasi Mandiri, PSBB (Pembatasan Sosial Berskala Besar), dan Herd Immunity" telah merubah pola aktivitas masyarakat, khususnya di Kota-kota. Sebelumnya, berkejar2an dengan waktu untuk meningkatkan pendapatan dengan jalan menambah produktivitas dan menekan biaya telah dikagetkan oleh adanya ancaman pandemi Covid19 yang ada dimana-mana, semangat berkejar-kejaran tersebut kendur seketika.

Kegiatan perdagangan di Kota-kota besar maupun kota kecil telah mengalami kelesuan untuk semua lapisan, mulai dari pedagang kecil mikro, pedagang asongan atau gerobak, pedagang toko, mini market sampai perdagangan berskala besar, super market, dan mallmall. Hal ini menyebabkan terjadinya pengangguran, berkurangnya pendapatan masyarakat dan menurun drastisnya penerimaan pemerintah dari pajak. Selama masa isolasi, para konsumen melakukan belanja dengan sangat hati-hati. Pihak produsen merasakan berkurangnya permintaan. Oleh karena itu, walaupun kebijakan Covid19 tidak menghambat aktivitas produksi pertanian di lahan secara langsung namun karena permintaan berkurang maka berkurang pula pendapatan petani yang mengusahakan kebun atau sawah.

Kebiasaan konsumen yang selama ini lebih banyak makan di luar rumah berubah menjadi lebih banyak makan di rumah sendiri, masak sendiri atau pesan antar. Berbelanja yang semula mencari tempat2 yang banyak di kerumuni orang berubah ke tempat yang tidak ada kerumunannya, artinya rasa enak dan harga murah tidak lagi menjadi patokan utama bagi konsumen. Mereka lebih mengutamakan sehat dan terjamin dalam proses pembuatannya. Kesadaran adanya ancaman bahaya serangan Covid19 terhadap nyawa setiap orang telah menyebabkan berubah nya psikologi dan sosial masyarakat. Sebelumnya berpikir materialis dan untung rugi dari setiap kerja, sekarang mulai nampak adanya kepedulian terhadap perintah agama melaksanakan sholat dan bersedekah. Mulai terlihat adanya aktivitas sosial di tengah-tengah kota, ada kegiatan membagikan nasi bungkus kepada kaum duafah dan lapisan bawah, kegiatan membagikan sembako, membagikan ampelop berisi uang kertas, sampai pada aktivitas memberikan tip berupa uang dalam setiap kali berbelanja di pedagang-pedagang kecil.

Harapan untuk semua aktivitas-aktivitas positif tersebut berlangsung tidak sementara tapi menjadi karakter bagi setiap orang. Kalau aktivitas sosial ini terus dipertahankan oleh pelaku yang telah memulai nya tentu akan diikuti juga oleh yang lainnya. Diharapkan juga setiap pelaku agribisnis berskala kecil, baik yang disektor produksi pertanian maupun sektor industri pengolahan dan perdagangan dapat mengantisipasi perubahan prilaku konsumen tersebut dengan perubahan pola produksi yang sesuai sehingga peluang bisnis yang terlepas dari pola sebelumnya dapat ditangkap.

Demikian semoga JALOW untuk penerbitan ini bermanfaat untuk kita semua aamiin ya robbal aalamiin.

Waalaikumsalam wbwb

Editor in Chief

Dr.Ir.Armen Mara,M.Si 
DAFTAR ISI

\begin{tabular}{|c|c|c|}
\hline 1 & $\begin{array}{l}\text { ANALISIS RESPON PENAWARAN KOMODITI KEDELAI } \\
\text { DI KABUPATEN TANJAB TIMUR } \\
\text { Oleh Edison }\end{array}$ & $1-10$ \\
\hline 2 & 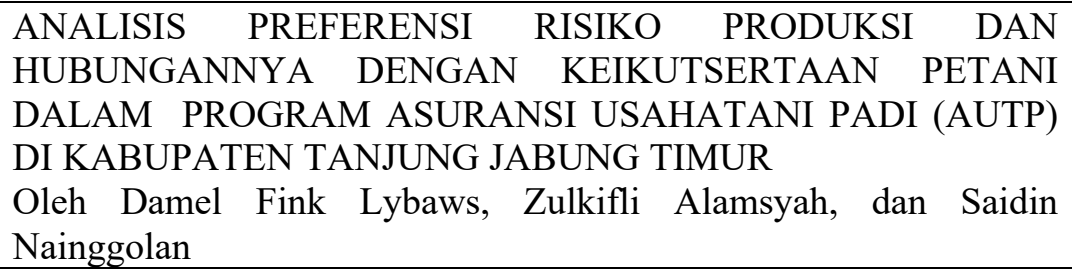 & $11-27$ \\
\hline 3 & $\begin{array}{l}\text { ANALISIS USAHA IKAN HIAS AIR TAWAR DI KOTA JAMBI (ANALYSIS } \\
\text { OF FRESH WATER ORNAMENTAL FISH IN JAMBI CITY) } \\
\text { Dody Hadisaputra, Ernawati, Suandi }\end{array}$ & $28-40$ \\
\hline 4 & $\begin{array}{l}\text { ANALISIS FAKTOR-FAKTOR YANG MEMPENGARUHI PRODUKSI } \\
\text { BOKAR (BAHAN OLAH KARET) DI KABUPATEN BATANGHARI } \\
\text { Oleh Elisabeth Lumban Gaol, Armen Mara, dan Riri Oktari UIma }\end{array}$ & $41-52$ \\
\hline 5 & $\begin{array}{l}\text { ANALISIS PENGAMBILAN KEPUTUSAN UNTUK PEMBELIAN } \\
\text { MAKANAN KEMASAN BERLOGO HALAL MUI (STUDI KASUS IBU } \\
\text { RUMAH TANGGA DI PERUMAHAN AUR DURI DAN PERUMNAS KOTA } \\
\text { BARU, KOTA JAMBI) } \\
\text { Oleh Putri Hana Jusia, Saad Murdy, Lavlinesia }\end{array}$ & $53-66$ \\
\hline 6 & \begin{tabular}{lrrrr} 
STRATEGI & ADAPTASI & PETANI & DALAM & \multicolumn{2}{l}{ MENGHADAPI } \\
RENDAHNYA & HARGA & JUAL & KELAPA & SAWIT DI \\
KECAMATAN & SUNGAI & BAHAR & KABUPATEN & MUARO \\
JAMBI & & & \\
Oleh Fiona Andini & ), Fuad Muchlis $^{2}$ ), Aulia Farida 2) \\
\end{tabular} & $67-73$ \\
\hline 7 & \begin{tabular}{lcllr}
\multicolumn{2}{l}{ KOLABORASI } & DALAM & PENGELOLAAN & \multicolumn{2}{c}{ PERKEBUNAN } \\
KELAPA SAWIT & RAKYAT & (STUDI KASUS: KUD & LUBUK \\
KARYA DAN & KUD & KAMPUNG & SURAU & KAB. \\
DHARMASRAYA & & & & \\
Oleh Yulistriani & & & & \\
\end{tabular} & $74-81$ \\
\hline 8 & $\begin{array}{l}\text { KEPUTUSAN PETANI SAWIT DALAM MENGKONVERSI } \\
\text { LAHAN KELAPA SAWIT MENJADI LAHAN PADI SAWAH DI } \\
\text { KECAMATAN BATANG ASAM KABUPATEN } \\
\text { TANJUNG JABUNG BARAT } \\
\text { Oleh Krielson Ompusunggu1), Arsyad Lubis2, Siti Kurniasih2 }\end{array}$ & $82-88$ \\
\hline 9 & $\begin{array}{l}\text { KAITAN BIAYA DAN TEKNIK PEREMAJAAN } \\
\text { KELAPA SAWIT RAKYAT } \\
\text { Oleh Nur Imdah Minsyah }\end{array}$ & $89-99$ \\
\hline 10 & $\begin{array}{l}\text { STRATEGI RANTAI PASOK KELAPA SAWIT DI PROVINSI } \\
\text { SUMATERA BARAT } \\
\text { Oleh Rahma Dzulqa1*), Rika Ampuh Hadiguna2) }\end{array}$ & 100 \\
\hline
\end{tabular}




\title{
KEPUTUSAN PETANI SAWIT DALAM MENGKONVERSI LAHAN KELAPA SAWIT MENJADI LAHAN PADI SAWAH DI KECAMATAN BATANG ASAM KABUPATEN TANJUNG JABUNG BARAT
}

\author{
Krielson Ompusunggu' ${ }^{11}$, Arsyad Lubis ${ }^{2}$, Siti Kurniasih ${ }^{2}$ \\ ${ }^{1}$ Mahasiswa Program Studi Agribisnis Fakultas Pertanian Universitas Jambi \\ ${ }^{2}$ Staff Pengajar Program Studi Agribisnis Fakultas Pertanian Universitas Jambi \\ ${ }^{1)}$ Penulis untuk korespondensi: Tel.+6285266852435 \\ email: Oppkrielson@gmail.com
}

\begin{abstract}
Farmers in Batang Asam Subdistrict have two choices, namely to join the Government's Revitalization program by converting their productive age oil palm plantations into paddy fields or exchanging land with other farmers or selling their land and then buying land in different places. The purpose of this study is to determine the factors that influence the decision of farmers to convert their oil palm plantation land into paddy fields. The approach used in this research is a quantitative approach. Primary data is collected through observation, interviews, and special discussions with selected speakers. The sampling method in this study was done by Simple Random Sampling Technique. The analysis tool used is the Godnes Of Fit Test with the same expected frequency. The results of this study indicate that the decision of farmers to convert their oil palm plantation land into lowland rice fields is influenced by psychological factors, the price factor of paddy fields, and the factor of two branches of farming.
\end{abstract}

Keywords: decision, land conversion

\section{PENDAHULUAN}

Lahan pertanian merupakan salah satu fungsi lahan yang digunakan untuk berusahatani. Lahan pertanian di Indonesia digunakan sebagai lahan perkebunan, lahan persawahan maupun hortikultura. Terutama lahan persawahan, yang cenderung ditanami tanaman padi memiliki arti yang sangat penting dalam upaya mempertahankan ketahanan pangan. Namun seiring perkembangan zaman, pertambahan penduduk, dan pertumbuhan ekonomi, eksistensi lahan pangan mulai terusik. Salah satu permasalahan yang cukup serius saat ini berkaitan dengan lahan pangan adalah makin maraknya alih fungsi lahan sawah ke penggunaan lainnya atau yang lebih dikenal dengan konversi lahan sawah.

Konversi lahan merupakan tindakan mengubah atau mengalihkan fungsi lahan yang awalnya dapat berupa lahan pertanian menjadi lahan non pertanian atau mengubah jenis komoditi yang ditanam dilahan tersebut. Tanaman sawit merupakan tanaman konversi pilihan para petani karena dapat dipanen dua kali dalam satu bulan jika sudah mencapai umur lima tahun, dibandingkan padi sawah yang hanya dapat dipanen dua kali 
dalam setahun. Mayoritas petani menjadi terbiasa mengkonversi lahannya menjadi lahan kelapa sawit karena prospek ekonomi yang dipandang jauh lebih baik, hasil panen lebih cepat dapat dinikmati dibanding menanam padi sawah yang memerlukan waktu beberapa bulan untuk panen membuat petani lebih memilih sawit sebagai komoditi konversi. Bagi petani dengan lahan sawah yang tidak terlalu luas menanam sawit cukup menguntungkan dibandingkan dengan menanam padi sawah. Demikian juga para petani di Provinsi Jambi, dimana pertanian merupakan salah satu sektor andalan bagi Provinsi Jambi. Provinsi Jambi mempunyai sembilan Kabupaten dan 2 Kota, yang masing - masing memiliki produksi tanaman padi sawah.

Provinsi Jambi memiliki sembilan Kabupaten dan dua kota. Diantara sembilan kabupaten tersebut, Kabupaten Tanjung Jabung Barat merupakan salah satu kabupaten lumbung padi terbesar bagi Provinsi Jambi dan juga memberikan kontribusi pada pangan nasional. Namun, di Kabupaten Tanjung Barat mengalami penurunan luas lahan sawah secara terus menerus setiap tahunnya. Pengurangan luas sawah di beberapa daerah ini didominasi oleh peralihan fungsi lahan menjadi perkebunan sawit. Perubahan tersebut dapat dilihat pada tabel berikut.

Tabel 1. Total luas lahan sawah dari seluruh jenis pengairan dan total luas lahan Kebun kelapa sawit rakyat di Kabupaten Tanjung Jabung Barat Tahun 2013-2016

\begin{tabular}{|l|c|c|c|c|}
\hline \multirow{2}{*}{ Jenis Lahan } & \multicolumn{4}{|c|}{ Tahun } \\
\cline { 2 - 5 } & $\mathbf{2 0 1 3}$ & $\mathbf{2 0 1 4}$ & $\mathbf{2 0 1 5}$ & $\mathbf{2 0 1 6}$ \\
\hline Sawah (Ha) & 18.777 & 15.012 & 10.818 & 10.319 \\
\hline $\begin{array}{l}\text { Kelapa Sawit } \\
\text { (Ha) }\end{array}$ & 50.265 & 57.029 & 61.960 & 63.554 \\
\hline
\end{tabular}

Sumber: BPS Tanjung Jabung Barat 2014 - 2017 (data diolah

Tabel 1 memperlihatkan bahwa di Kabupaten Tanjung Jabung Barat dari tahun 2013 hingga 2016 mengalami penurunan luas lahan sawah terus menerus, sementara luas kebun kelapa sawit rakyat mengalami peningkatan secara terus menerus pula. Sehingga dapat disimpulkan bahwa peralihan fungsi lahan atau konversi lahan dari sawah menjadi perkebunan sawit bukanlah merupakan hal yang baru. Kendati demikian, di Kabupaten Tanjung Jabung Barat masih ada beberapa kecamatan dengan desa yang masih memiliki lahan sawah yang cukup luas bagi desa tersebut.

Desa Sri Agung dan Rawa Medang merupakan dua desa yang terletak di Kecamatan Batang Asam Kabupaten Tanjung Jabung Barat. Desa ini merupakan transmigrasi, dan mayoritas mata pencaharian masyarakatnya yaitu petani padi sawah di tengah perkebunan sawit di Kabupaten Tanjung Jabung Barat yang kian meluas. Namun, tidak sedikit petani di dalam maupun luar daerah ini memilih perkebunan sawit sebagai sumber ekonomi mereka. Walaupun demikian sebagai desa yang mengalami pemekaran, kedua desa ini merupakan salah satu sentra lumbung padi bagi Kabupaten Tanjung Jabung Barat. Bahkan masyarakat petani daerah tersebut banyak yang menjual hasil pertanian ke luar provinsi. 
Maraknya masyarakat petani melakukan konversi lahan sawah menjadi perkebunan sawit, tetapi di Desa Sri Agung dan Desa Rawa Medang masyarakat petani melakukan konversi lahan yang sebaliknya, yaitu mengkonversi lahan perkebunan kelapa sawit usia produktif meeka menjadi lahan padi sawah sebagai hasil dari keputusan para petani atas pilihan yang diberikan pemerintah kepada mereka yaitu mengikuti anjuran repitalisasi atas lahan kebun kelapa sawit mereka atau memindahkan lahan kebun kelapa sawit mereka. Pengembalian fungsi lahan atau Repitalisasi atas lahan kebun kelapa sawit milik petani dengan cara melakukan penebangan tanaman perkebunan kelapa sawit di lahan tersebut dan diganti menjadi sawah baru sebanyak 40 hektar di Desa Sri Agung dan 70 hektar di Desa Rawa Medang. Tentunya ada banyak faktor yang dapat mempengaruhi keputusan petani tersebut.

\section{METODE}

Penelitian ini dilaksanakan di Kecamatan Batang Asam. Lokasi ini ditentukan secara sengaja (purposive) dengan pertimbangan bahwa Kecamatan Batang Asam merupakan salah satu daerah sentral tanaman pangan di Kabupaten Tanjung Jabung Barat. Khususnya Desa Sri Agung dan Desa Rawa Medang yang mayoritas masyarakatnya menggantungkan hidupnya dengan bertani. Desa Sri Agung dan Desa Rawa Medang merupakan lokasi percetakan sawah yang sebelumnya merupakan lahan kebun kelapa sawit. Penelitian ini dilakukan selama dua bulan yaitu dari bulan Juli hingga Agustus 2019.

Penelitian ini menggunakan pendekatan kuantitatif. Data primer dikumpulkan melalui observasi, wawancara, serta diskusi khusus dengan narasumber terpilih. Metode penarikan sampel dalam penelitian ini dilakukan dengan Teknik Acak Sederhana atau Simple Random Sampling. Sampel yang sudah ditentukan kemudian melengkapi data yang diberikan, begitu seterusnya hingga mencakup seluruh sampel.

Data yang telah berhasil dihimpun terlebih dahulu dilakukan sortasi, tabulasi, serta pemberian skor. Pemberian skoring dilakukan untuk mengkuantifikasikan data kualitatif dengan menggunakan skala ordinal, yaitu skala yang disusun berdasarkan atas jenjang dalam atribut tertentu. Selanjutnya data dianalis secara deskriptif dan statistik non parametrik. Alat anlisis yang digunakan yaitu Uji Godnes Of Fit dengan frekuensi yang diharapkan sama. Hasil analisis disajikan dalam bentuk tabel distribusi frekuensi kemudian dideskripsikan.

\section{HASIL DAN PEMBAHASAN}

Gambaran Umum Lokasi Penelitian

Secara Geografis Kecamatan Batang Asam Kabupaten Tanjung Jabung Barat terletak pada $0^{\circ} 53^{\prime}-1^{\circ} 41^{\prime}$ lintang selatan dan $103^{\circ} 23^{\prime}-104^{\circ} 31^{\prime}$ bujur timur serta memiliki Luas wilayah $\pm 1.042,37 \mathrm{~km}^{2}$ dengan populasi $293.594 \mathrm{jiwa}$. Batas - batas wilayah Kabupaten Tanjung Jabung Barat yaitu sebelah utara berbatasan dengan Kecamatan Kemuning Inhil Riau, sebelah selatan berbatasan dengan Kecamatan Renah Mendaluh, sebelah barat berbatasan dengan Kabupaten Tebo dan Inhil Provinsi Riau, sebelah timur berbatasan dengan Kecamatan Tungkal Ulu. Luas lahan tanaman pangan dan hortikultura yang ada di Kecamatan Batang Asam yakni 1929 Ha. Jumlah penduduk di Kecamatan Batang Asam pada tahun 2017 tercatat sebanyak 29.539 jiwa yang terdiri dari penduduk 
laki-laki 15.510 jiwa dan penduduk perempuan 14.029 jiwa. Kepadatan penduduk di Kecamatan Batang Asam tercatat 28,34 per $\mathrm{Km}^{2}$. Secara umum mata pencaharian penduduk di Keamatan Batang Asam adalah petani, baik di sektor tanaman pangan ataupun tanaman perkebunan, sedangkan pegawai negeri, swasta dan sektor lainnya hanya sebagian kecil saja. Sarana dan prasarana di Kecamatan Batang Asam meliputi transportasi (mobil, sepeda motor) komunikasi (telepon genggam, radio, televisi) dan pemasaran (toko, pasar, tengkulak, minimarket, BUMDES, serta KUD). Sarana dan prasarana tersebut cukup memadai dalam rangka menunjang kegiatan usahatani. Kecamatan Batang Asam memiliki cukup banyak kelompok tani pada beberapa desanya. Desa Sri Agung memiliki 13 Kelompok Tani dan Desa Rawa Medang memiliki 15 Kelompok tani. Wilayah Kecamatan Batang Asam untuk luas penggunaan lahan sawah yakni 1929 $\mathrm{Ha}$ dan untuk luas penggunaan lahan perkebunan yaitu $12.000 \mathrm{Ha}$.

Faktor Psikologis Mempengaruhi Keputusan Petani dalam Mengkonversi Lahan Kebun Kelapa Sawit Menjadi Lahan Padi Sawah di Desa Sri Agung Dan Rawa Medang.

Berdasarkan analisis statistik Uji Goodness of Fit terhadap faktor psikologis di desa Sri Agung dan Desa Rawa Medang, diperoleh nilai Chi Square $\left(X^{2}\right)$ hitung sebesar 31,33. Nilai Chi Square $\left(X^{2}\right)$ hitung tersebut lebih kecil dari nilai Chi Square $\left(X^{2}\right)$ tabel $(\mathrm{df}=118$ 1) sebesar 143,246 dengan taraf nyata $5 \%(31,33<143,24)$, maka Ho diterima atau H1 ditolak. Artinya tidak terdapat perbedaan antara frekuensi yang terjadi dengan frekuensi yang diharapkan. Dari hasil analisis faktor psikologis tersebut maka dapat ditarik kesimpulan hipotesisnya yaitu faktor psikologis berpengaruh terhadap keputusan petani dalam mengkonversi lahan kelapa sawit menjadi lahan padi sawah di Desa Sri Agung dan Rawa Medang Kecamatan Batang Asam Kabupaten Tanjung Jabung Barat.

Menurut Kotler (2008), keputusan seseorang dapat dipengaruhi oleh faktor psikologis. Faktor psikologis ini meliputi pembelajaran, keyakinan dan sikap. Petani dalam mengambil keputusannya dapat juga dipengaruhi oleh hal-hal tersebut sebagai faktor psikologi petani. Berikut gambaran seluruh skor jawaban responden dari pertanyaan faktor psikologis mempengaruhi keputusan petani yang diperoleh dari kuisioner penelitian di Desa Sri Agung dan Desa Rawa Medang.

Tabel 2. Gambaran Total Skor Jawaban kuisioner Faktor Psikologis Terhadap Keputusan Petani di Desa Sri Agung dan Rawa Medang

\begin{tabular}{llc}
\hline No & Indikator & Nilai \\
\hline 1 & Nilai Rata-rata (Mean) & 22,07 \\
2 & Nilai Yang Sering Muncul (Modus) & 24 \\
3 & Nilai Tengah (Median) & 22 \\
4 & Nilai Maksimal & 24 \\
5 & Nilai Minimal & 8 \\
\hline
\end{tabular}

Sumber : Hasil Olahan Data Primer 2019

Tabel 2 menjelaskan tentang gambaran seluruh skor jawaban kuisioner faktor psikologis di Desa Sri Agung dan Rawa Medang, memiliki kecenderungan bernilai tinggi. Jumlah pertanyaan yang diajukan kepada responden sebanyak delapan pertanyaan, bila 
responden menjawab "TIDAK" maka bernilai satu dan bila responden menjawab "YA" maka bernilai tiga. Dengan demikian skor minimalnya adalah delapan dan skor maksimalnya adalah 24. Dari skor delapan sampai dengan 24, total skor yang paling sering muncul yaitu skor bernilai 24 dengan rata-rata 22,07. Hal ini menunjukkan bahwa hampir seluruh responden menjawab " $Y A$ " terhadap pertanyaan faktor psikologis mempengaruhi keputuan yang diajukan dalam kuisioner tersebut.

Faktor Harga Lahan Persawahan dan Dua Cabang Usahatani Mempengaruhi Keputusan Petani dalam Mengkonversi Lahan Kebun Kelapa Sawit Menjadi Lahan Padi Sawah di Desa Sri Agung Dan Rawa Medang.

Berdasarkan pengamatan lebih lanjut terhadap jawaban petani sampel melalui kuisioner terbuka, serta hasil diskusi khusus bersama PPL dan beberapa Ketua Gapoktan, diperoleh beberapa faktor lainnya yang tidak berkaitan dengan ketiga faktor yang mempengaruhi keputusan petani tersebut, namun juga memiliki pengaruh yang cukup besar terhadap keputusan petani dalam mengkonversi lahan kelapa sawit menjadi lahan padi sawah di Desa Sri Agung dan Desa Rawa Medang diantaranya, pertama yaitu sebagian besar petani responden lebih memilih melakukan dua cabang usahatani sekaligus, usahatani padi sawah dan berkebun kelapa sawit. Petani menganggap bahwa dengan melakukan dua cabang usahatani sekaligus lebih menguntungkan bagi petani. Petani dapat memenuhi kebutuhan makanan pokok keluarganya yaitu beras, yang dihasilkan melalui usahatani padi sawah setiap tahun. Sedangkan untuk kebutuhan lainnya seperti sandang dan papan, biaya pendidikan anak, serta biaya lainnya dapat terpenuhi melalui hasil penjualan buah kelapa sawit. Walaupun petani sering mengalami kerugian dalam berkebun kelapa sawit terutama dikarenakan harga yang tidak sesuai harapan, tetapi mereka dapat melakukan subtitusi diantara kedua usahatani tersebut yaitu dari hasil panen padi yang diusahakan tersisa di luar dari kebutuhan pokok beras, kemudian dijual untuk menambah pendapatan bila pendapatan dari kebun kelapa sawit tidak sesuai harapan, tujuannya agar pemenuhan semua kebutuhan dapat diusahakan terpenuhi oleh petani. Di samping itu, harga beras yang relatif stabil dan sesuai harapan petani yaitu berkisar 4500 rupiah per kilogram beras atau 8.800 rupiah per kilogram gabah kering, serta mayoritas petani memiliki lahan padi sawahnya sendiri dan dikerjakan bersama keluarga, juga mendukung hal tersebut.

Faktor lainnya yang juga memiliki pengaruh yang cukup besar terhadap keputusan petani dalam mengkonversi lahan kelapa sawit menjadi lahan padi sawah di Desa Sri Agung dan Desa Rawa Medang, yaitu dikarenakan harga lahan persawahan di daerah ini cenderung sangat mahal. Bila dibandingkan dengan harga lahan kebun kelapa sawit sekitar 50 sampai 70 juta per hektar, lahan persawahan memiliki harga empat hingga lima kali lipat dari harga lahan kebun kelapa sawit, yaitu sekitar 200 sampai 400 juta per hektar lahan persawahan. Hal ini kemungkinan besar disebabkan oleh kondisi geografis dan topografi daerah tersebut yang memang sebagian besar terletak di dataran rendah yang dikelilingi bukit dan memiliki alira-aliran sungai, sehingga cocok untuk persawahan. Di samping itu, aliran irigasi yang cukup baik dan memadai untuk mengairi 
hampir seluruh areal persawahan juga mendukung harga lahan persawahan tersebut menjadi tinggi.

\section{KESIMPULAN}

Berdasarkan hasil penelitian yang telah dilaksanakan dan diuraikan tentang faktorfaktor yang mempengaruhi keputusan petani dalam mengkonversi lahan kelapa sawit menjadi lahan padi sawah di Desa Sri Agung dan Desa Rawa Medang, maka dapat di tarik kesimpulan bahwa Faktor-faktor yang mempengaruhi keputusan petani dalam mengkonversi lahan kelapa sawit menjadi lahan padi sawah di Desa Sri Agung dan Desa Rawa Medang Kecamatan Batang Asam Kabupaten Tanjung Jabung Barat yaitu faktor psikologis, faktor dua cabang usahatani, serta faktor harga lahan persawahan.

Mengacu pada hasil penelitian, maka penulis menyarankan untuk petani diharapkan dapat mempertahankan faktor-faktor yang mempengaruhi keputusannya tersebut karena bernilai positif bagi dirinya agar tetap memiliki kepercayaan diri untuk mengoptimalkan produktivitas padi sawah yang dimilikinya saat ini. Pemerintah terkait juga bersama PPL diharapkan dapat mempertahankan hasil repitalisasi yang positif tersebut terhadap petani dengan tetap memberikan dukungan perhatian, inovasi, serta kebutuhan-kebutuhan primer lainnya bagi petani dalam melakukan usahatani padi sawahnya di tengah usaha kebun kelapa sawit milik masyarakat maupun perusahaan swasta

\section{DAFTAR PUSTAKA}

Anggari, dkk. 2016. Alih Fungsi Lahan Sawah Ke Perkebunan Kelapa Sawit di Kecamatan Trumon Kabupaten Aceh Selatan Tahun 2005-2014. Jurnal. Program Studi Pendidikan Sejarah FKIP Universitas Syiah Kuala. Aceh.

Atmosudirdjo Prajudi. 1982. Beberapa Pandangan Umum Tentang Pengambilan Keputusan (Decisions Making). Seri Pustaka Ilmu Administrasi VI. Ghalia Indonesia. Jakarta Timur.

Aziz, M. 2017. Faktor-faktor Yang Mempengaruhi Keputusan Petani Kopi Menjual Hasil Produksi Kepedagang Pengumpul di Kecamatan Betara Kabupaten Tanjung Jabung Barat. Skripsi. Program Studi Penyuluhan dan Komunikasi Pertanian Jurusan Agribisnis Fakultas Pertanian Universitas Jambi. Jambi.

BPS Kabupaten Tanjung Jabung Barat. Kabupaten Tanjung Jabung Barat Dalam Angka. BPS Tanjung Jabung Barat. Jambi.

BPS Kabupaten Tanjung Jabung Barat. Kecamatan Batang Asam Dalam Angka. BPS Tanjung Jabung Barat. Jambi.

Kotler dan Amstrong. 2008. Prinsip-prinsip Pemasaran. Jilid 1. Edisi ke-12. Jakarta. Erlangga

Lambok Albert. 2016. Faktor-Faktor Yang Mempengaruhi Keputusan Petani Dalam Mempertahankan Lahan Padi Sawah dari Konversi Menjadi Lahan Kelapa Sawit (Kasus :Desa Tanjung Ibus, Kecamatan Secanggang, Kabupaten Langkat). Jurnal. Program Studi Agribisnis Fakultas Pertanian Universitas Sumatera Utara. Sumatera Utara 
Mirnawati. 2018. Faktor-faktor Yang Mempengaruhi Keputusan Petani dalam Pola Tanam Tumpang Gilir (Multiple Cropping) di Kecamatan Berbak Kabupaten Tanjung Jabung Timur. Skripsi. Program Studi Penyuluhan dan Komunikasi Pertanian Jurusan Agribisnis Fakultas Pertanian Universitas Jambi. Jambi.

Priyono. 2016. Metode Penelitian Kuantitatif. Edisi Revisi 2016. Zifatama Publishing. Sugiyono. 2015. Statistik Nonparametris Untuk Penelitian. Cetakan ke-12. Alfabeta. Bandung.

Syamsi Ibnu. 1989. Pengambilan Keputusan (Decisions Making). Cetakan Pertama. Bina Aksara. Jakarta. 